\title{
Trail Marking and Processionary Behavior of the Larvae of the Weevil Phelypera distigma (Coleoptera: Curculionidae)
}

\author{
T. D. Fitzgerald, ${ }^{1,5}$ A. Pescador-Rubio, ${ }^{2}$ M. T. Turna, ${ }^{3}$ and J. T. Costa ${ }^{4}$
}

Accepted March 17, 2004; revised June 2, 2004

We present here the results of an investigation of the behavioral bases of the first documented instance of trail marking and processionary behavior in a beetle. The larvae of Phelypera distigma (Coleoptera: Curculionidae) forage communally, moving over the host plant in head-to-tail processions. Our study shows that the larvae secrete a pheromone from the ventral surface of the posterior abdomen that both elicits and guides the collective locomotion of the cohort. The pheromone is soluble in acetone and other nonpolar solvents and is relatively short-lived, eliciting trail following for less than $4 h$ after its deposition. When in processionary formations, larvae stimulate locomotion in others by rapidly bobbing their heads against sets of setae that occur on the lateral flanks of the posterior tips of the abdomens of precedent individuals. Larvae are also strongly attracted to tactile or chemotactile stimuli found at the tip of the abdomen of other larvae and their response to lures made of eviscerated abdomens show that such stimuli take precedence over the trail pheromone in eliciting and orienting locomotion. The cycloalexic formations adopted by resting larvae maximize the amount of body contact possible in a two-dimensional aggregate and allow tactile signals to rapidly

\footnotetext{
${ }^{1}$ Department of Biological Sciences, State University of New York at Cortland, Cortland, New York 13045.

${ }^{2}$ Universidad de Colima, Centro Universitario de Investigación y Desarrollo Agropecuario, Colima, Mexico.

${ }^{3}$ Department of Biological Sciences, Binghamton University, Binghamton, New York.

${ }^{4}$ Department of Biology, Western Carolina University, Cullowhee, North Carolina.

${ }^{5}$ To whom correspondence should be addressed. E-mail: fitzgerald@cortland.edu.
} 
radiate through the groups, alerting all members of a cohort to the onset of bouts of activity.

KEY WORDS: Phelypera distigma; trail pheromone; processionary; foraging; Curculionidae.

\section{INTRODUCTION}

Processionary behavior is a coordinated form of locomotion in which cohorts of insects travel single file in head-to-tail contact. The behavior is distinct from trail following in that trail followers move independently and typically at a distance from each other, referencing a trail marker rather than contact stimuli associated with the bodies of siblings to stay in line.

Within the Insecta, processioning has been previously described only from social caterpillars. It occurs most commonly in the subfamily Hemileucinae of the Saturniidae (Lepidoptera) (Tuskes et al., 1996) and has been investigated in Hemileuca (Capinera, 1980) and Hylesia (Janzen, 1984; Wolfe, 1988; Fitzgerald and Pescador-Rubio, 2002). It is also particularly well developed in the Notodontidae genera Thaumetopoea (Fabre, 1916; Demolin, 1969; Huchon and Demolin, 1970; Fitzgerald, 2003) and Orchrogaster (Mills, 1950, 1951a,b; VanSchagen et al., 1992; Floater, 1996a,b). Sawfly caterpillars in the genus Perga (Hymenoptera: Symphyta) are the only nonlepidopteran species previously reported to move together in procession-like formations (Weinstein and Maelzer, 1997) but their behavior has yet to be studied.

While processionary behavior is uncommon in the Insecta, many species of social insects engage in trail-based foraging behavior. Trail marking is ubiquitous among the ants (Formicidae) and termites (Isoptera)(Wilson, 1971) and has been reported from the social caterpillars of a number of lepidopteran and symphytan species as well (Fitzgerald, 1995; Fitzgerald and Underwood, 1998a,b; Fitzgerald and Costa, 1999; Costa and Louque, 2001; Ruf et al., 2001; Flowers and Costa, 2003; Ruf, 2002; Costa et al., in press). Despite the vastness of the Coleoptera and the great diversity of behaviors found among its members, it is noteworthy that there have been no prior studies of either trail-based communal foraging or processionary behavior for any member of the order. To our knowledge, the larvae of the curculionid weevil, Phelypera distigma (Boheman), we report on here is the first beetle to be shown to mark and follow chemical trails and to engage in processionary behavior.

Weevils in the genus Phelypera are found only in Central and South America. P. distigma is the most northerly distributed of the 14 described species (Wibmer and O'Brien, 1986). The seasonal life history of the 
beetle at our study site in Jalisco, Mexico, appears similar to that reported for the insect by Janzen (1979) for populations he studied in Costa Rica. There is a single generation per year. Overwintered adults appear in late June and early July in Mexico and lay eggs on the leaves of Guazuma ulmifolia Lam. (Sterculiaceae). The eggs hatch shortly thereafter and the larvae feed gregariously on the young leaves, typical aligned side by side in contact with one another. The larvae rest in distinctive circular formations between bouts of feeding (Janzen, 1979) termed cycloalexic formations by Jovilet et al. (1991). Development is rapid; larvae reach maturity in as little as a week, then pupate on the leaves in silk-covered cocoons. Adults eclose about 5 days later and then, after spending a week or two feeding on leaves, disappear until the following year.

Observations made of colonies of $P$. distigma reported elsewhere (Costa et al., 2004) show that the larvae move frequently as they forage on the leaves of the host plant, travelling on average $40 \mathrm{~cm}$ from one feeding site to another. During these forays, the larvae move together in processions of 2 to as many as 30-40 individuals. We report here the results of a study to determine the role of chemical and physical stimuli in the formation and maintenance of these processions.

\section{MATERIALS AND METHODS}

\section{Study Site and Source of Experimental Colonies}

The study was conducted at the Estación de Biología Chamela (U.N.A.M.), Jalisco, Mexico $\left(19^{\circ} 30^{\prime} \mathrm{N}, 105^{\circ} 03^{\prime} \mathrm{W}\right)$, during early July of 2002 and 2003. Larvae used in these studies were collected from G. ulmifolia trees near the station or from trees found east of Manzanillo, Mexico $\left(19^{\circ} 04^{\prime} \mathrm{N}, 104^{\circ} 12^{\prime} \mathrm{W}\right)$. Studies were conducted under a temperature regime similar to that experienced by larvae in the field in an indoor facility open to outside air. Temperature during the daily study periods varied between 25 and $32^{\circ} \mathrm{C}$. Unless otherwise noted, larvae used in the studies outlined below were allowed to feed ad libitum and collected just prior to use from host tree branches maintained in the laboratory.

\section{Experimental Studies}

\section{Formation and Maintenance of Processions}

To determine how processions were formed, colonies of larvae were removed from leaves and placed at the centers of sheets of paper $49 \mathrm{~cm}$ 
wide by $62 \mathrm{~cm}$ long and allowed to assemble ad libitum. The larvae often formed processions spontaneously within several minutes but occasionally needed to be prodded with a brush to encourage them to assemble. Processions were observed directly to obtain information on the way in which the larvae assembled and on the role of tactile and chemical stimuli in their organization. We also videotaped the feeding, trail following, and processionary behavior of larvae as they foraged on host plants for more detailed analysis. A total of 27 episodes were videotaped having an average duration of $227 \pm 36 \mathrm{~min}$ (SE). Episodes were filmed in real time or in time lapse at the rate of $1 \mathrm{fps}$. Episodes filmed at night were illuminated with IR light provided by a bank of LEDs and recorded with an IR-sensitive camera ( $\mathrm{x}$-10 wireless video camera).

\section{Deposition of a Persistent Trail Marker}

Investigations were undertaken to determine if single larvae deposit persistent trails that orient and stimulate the locomotion of others. A larva was taken from a host leaf and placed at the center of a paper card. When the insect began to move, its pathway was indicated with pencil marks placed at approximate $1-\mathrm{cm}$ intervals for a distance of at least $5 \mathrm{~cm}$. The larva was then removed and a second larva immediately placed at the origin of the marked pathway and observed to determine if it followed it. A response was considered positive if the test larva followed the pathway precisely from beginning to end. The study was replicated 20 times, each time with different larvae. Preliminary studies showed that the pencil marks had no apparent effect on larval behavior and in themselves served to neither stimulate nor orient locomotion.

\section{Longevity of the Trail Marker}

Studies have shown that the larave of social Lepidoptera produce long-lived trails, facilitating the movement of caterpillars over repeatedly used pathways (Fitzgerald, 1995; Fitzgerald and Underwood, 1988a,b; Ruf et al., 2001; Ruf, 2002; Costa et al., in press). The caterpillars may also distinguish between new and aged trails, facilitating both the cohesion of groups as they move over previously marked branches and the abandonment of old trails that lead to exhausted feeding sites (Peterson and Fitzgerald, 1991; Fitzgerald and Underwood, 1998a,b; Ruf et al., 2001; Ruf, 2002). To assess the persistence of the larval trail of $P$. distigma, and the ability of the larvae to discern trail age, trails were established by allowing two larvae to move together in procession over a paper card for at least $5 \mathrm{~cm}$. The pathway of the larvae was marked with pencil as described above. The pathway was then tested to determine if it elicted trail following by placing a larva 
at its origin $0.5,1,2$, or $4 \mathrm{~h}$ after it was initially deposited. A response was considered positive if the larva followed the marked pathway for its whole length. The test was replicated 10 times at each age interval, each time with different test larvae and different trails. These studies were conducted on paper index cards since preliminary studies showed that larvae readily marked the cards and the cards provided a convenient and uniform substrate for our studies. Under field conditions, larvae form trails on leaves and branches and they may advance over nonhost substrate as well. Since the chemical trail could be more or less persistent on a natural substrate, we replicated this test 10 times at each of two age intervals on Guazuma leaves. Leaf trails were tested for persistence 0.5 and $4 \mathrm{~h}$ after they were initally deposited.

\section{Response of Larvae to Extracted Pheromone}

We observed the response of larvae to artificial trails made from wholebody extracts. To determine the best solvent, we extracted separate groups of 10 larvae for $1 \mathrm{~h}$, each in a series of solvents with decreasing affinity for polar compounds: ethanol, acetone, ether, and hexanes. Solvents were drawn off and concentrated to $0.25 \mathrm{ml}$. Artificial trails were prepared by laying out $20-\mu \mathrm{l}$ quantities of the concentrated extracts in narrow lines $4 \mathrm{~cm}$ long on paper cards. After the solvent had completely evaporated, a larva was placed at the head of a trail and its response observed. Following these preliminary screenings, we prepared a stock solution by extracting $100 \mathrm{ma}-$ ture larvae in the most effective of the solvents. After soaking the larvae for $4 \mathrm{~h}$ in $3 \mathrm{ml}$ of the solvent, the solvent was drawn off, percolated though an $8 \mathrm{~cm}$ long $\times 0.6 \mathrm{~cm}$ diameter column of florisil with excess solvent to remove particulates, and concentrated by evaporation to $1 \mathrm{ml}$. The response of larvae to the extract and a solvent control was then compared with a two-choice apparatus (Fig. 1A and B). The apparatus consisted of a central runway and two parallel choice arms, situated on each side of the runway. Five-microliter quantities of the extract or solvent (control) were placed on the choice arms. A larva was placed on the runway and its choice of arm recorded. A response was considered positive it the larvae selected and walked the whole length of the arm. An apparatus was used only once and the arm to which the treatment and control were applied was alternated for each test to preclude a positional bias.

\section{Source of the Trail Marker}

Previous studies of trail-marking social caterpillars show that in most species trail pheromones are secreted from the ventral surface of the posterior tip of the abdomen (Fitzgerald, 1995; Fitzgerald and Underwood, 

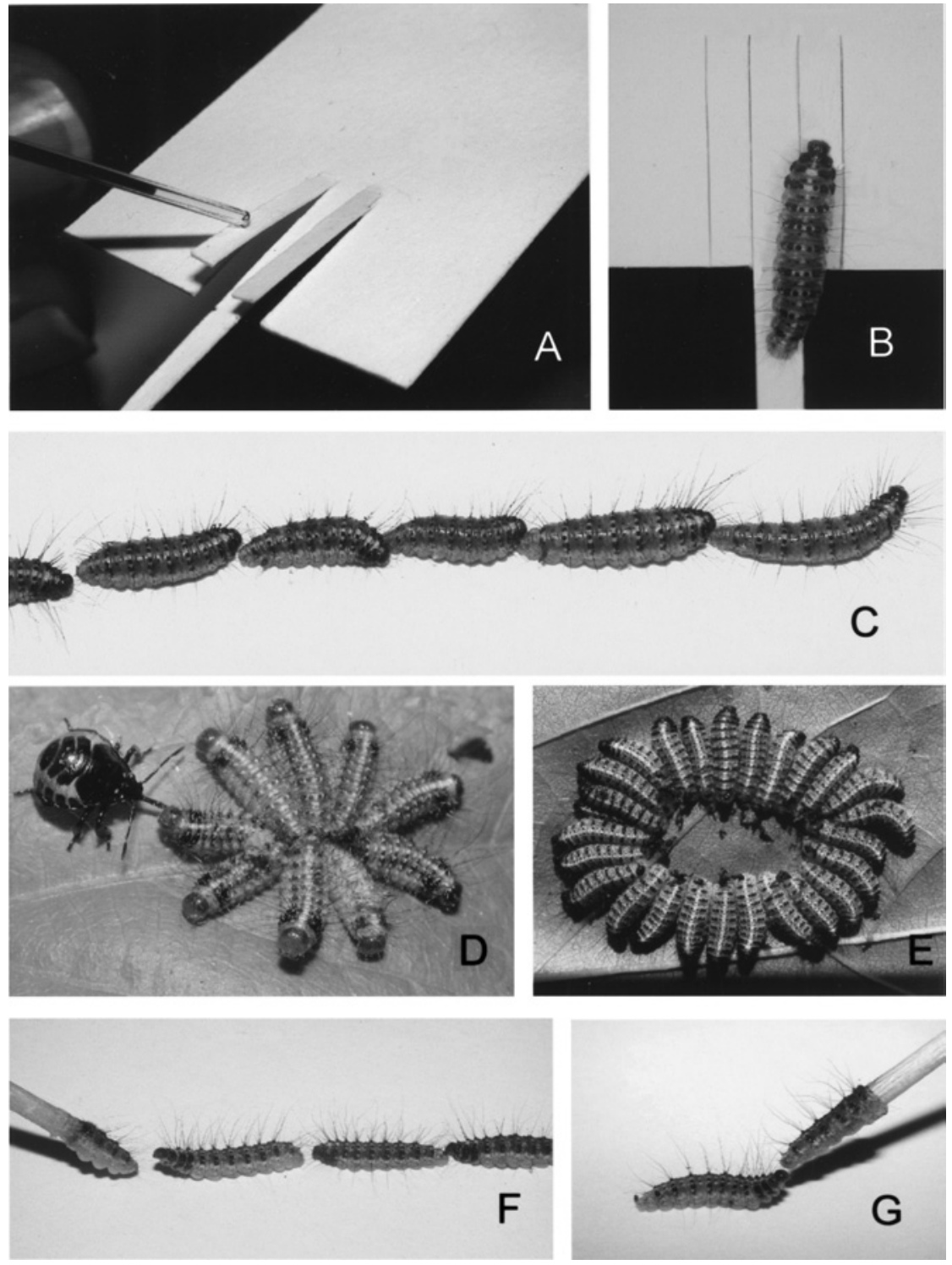

Fig. 1. (A) Two-choice apparatus. (B) Response of a $P$. distigma larvae in two-choice apparatus. (C) A procession of $P$. distigma larvae. (D) Cycloalexic formation of $P$. distigma attacked by a pentatomid bug. (E) Cycloalexic formation of $P$. distigma. (F and G) Procession and individual of $P$. distigma following lures prepared from the eviscerated abdomens of $P$. distigma larvae. 
1998a,b; Fitzgerald and Pescador-Rubio, 2002; Ruf et al., 2001; Fitzgerald, 2002; Ruf, 2002). In the eusocial insects, trail pheromones are also typically secreted from the posterior tip of the abdomen (Wilson, 1971). Several different procedures were used to determine the site of secretion of the trail marker of $P$. distigma. Initially, small strips of paper were attached with super glue to the undersides of the tips of the abdomens of each of five mature larvae to prevent the surfaces of these terminal segments (abdominal segments 7-9) from contacting the substrate, a technique previously described by Fitzgerald and Pescador-Rubio (2002) and Fitzgerald (2003). The strip extended approximately $1 \mathrm{~mm}$ beyond the tip of the larva's abdomen. To facilitate this procedure, larvae were immobilized by placing them in a freezer at approximately $-16^{\circ} \mathrm{C}$ for $1 \mathrm{~min}$. A chilled larva was then turned upside down and viewed under a dissecting microscope to enable the accurate placement of the paper strip. Larvae recovered from the procedure within minutes but were held for at least $15 \mathrm{~min}$ before they were used. To determine if they could still mark trails even though their terminal segments were prevented from contacting the substrate by the paper strips, the larvae were placed on paper cards, and their pathways marked with pencil as they moved over the card. Intact larvae were then placed at the origin of each of the pathways to determine if the treated caterpillar left a trail. After assessing the results of this procedure, we conducted another series of tests in which a mature larva was allowed to lay down a trail on a paper card and its pathway marked with spaced pencil dots for a distance of at least $5 \mathrm{~cm}$. The larvae were then quickly lifted from the card with a forceps and the last position of both ends of its body marked. A second instar larva was then placed at the origin of the pathway and closely observed as it entered the region last occupied by the marking caterpillar to determine the exact point at which it detected the end of the trail. We considered the terminaton of the trail to be at or slightly posterior to the point where the larva abruptly hesitated, swung the anterior portion of its body from side to side in an attempt to find the trail, then turned back. The test was replicated 13 times.

After evaluating the results of the above study, we attached paper strips to the undersides of each of segments 3-6 separately (two replicates each) and of segments 3 and 4 together (five replicates) and 5 and 6 together (eight replicates). It was not possible to block more than two segments at a time without interfering with the ability of the larvae to locomote. We used the same experimental protocol as described above for strips used to block the terminal segments, to assess the effect of these treatments on the ability of larvae to mark trails.

In a procedure to further isolate the source of the pheromone, we collected surface residues from candidate sites on the ventral surface of the 
abdomen, with a technique previously employed in the study of other social caterpillars (Fitzgerald and Underwood, 1998a; Ruf, 2002; Fitzgerald, 2003; Costa et al., in press). Briefly, a 5-cm square of paper was folded along both diagonals to form four ridges that intersected at the center of the square when the paper was unfolded. While the paper was still folded, one of the four ridges was swiped three times against a designated site on the ventral surface of a full grown larva to collect surface residue. Residue was then swiped three times from a different designated body site on a ridge of the sheet that formed a right angle to the first marked ridge. The paper was then unfolded and flattened and a larva placed at the center with its head at the origin of the two treated ridges and observed to determine which if either of the two it followed. A response was considered positive if a larva followed a ridge for its entire length. Observations of larvae walking upside down in Petri plates showed that they fully spread their abdominal prolegs as they advance over the substrate so that the inner surface of the prolegs and the region between the prolegs is in intimate contact with the substrate. When lifted from the substrate, however, the larvae immediately brought together the prolegs of a segment. Thus, to collect surface residue for these studies, the ridge of the card was swiped between the apposed prolegs of the candidate segments. To do this with exactness, it was necessary to work under a dissecting microscope while grasping the larvae between a thumb and a forefinger. Using this procedure, we conducted tests to compare the response of larvae to surface residue collected from the venter and inner surface of the prolegs in the region of segments 5 and 6 with that collected from the region of segments 3 and 4 and from the region of segments 7-9.

After assessing the results of these studies, we searched for potential sites of secretion by both light microscopy and scanning electron microscopy (SEM). To prepare the larvae for light microscopy, mature larvae were placed in a $5 \%$ solution of potassium hydroxide heated to $80^{\circ} \mathrm{C}$ to dissolve all soft tissues. The exoskeleton was then rinsed in ethanol and cleaned of debris. The cleared exoskeleton was cut lengthwise to expose the inside of the integument, placed under a cover slip, and observed under a microscope. Four larvae were prepared for inspection in this manner. To prepare specimens for SEM, living larvae were dropped into boiling water for several seconds, fixed in $4 \%$ glutaraldehyde, and then serially dehydrated in increasingly concentrated ethanol. To facilitate viewing, a $0.34-\mathrm{mm}$ diameter wire was placed between the abdominal prolegs to force them apart and left there until the completion of the ethanol dehydration series. Critical point drying was performed with a Tousimis Samdri PVT-3B. After sputter coating, specimens were scanned with an ISI Supra 
IIIA-K scanning electron microscope. A total eight larvae were prepared for scanning in this manner.

\section{Response of Larvae to Trails of Different Strength}

A study was conducted to determine if the larvae discriminated between pathways of different numbers of larvae. Pathways were obtained by letting individuals or processions of either 5 or 10 larvae move over paper cards. The pathways of the larvae were indicated with spaced pencil marks. Sections $2 \mathrm{~cm}$ long $\times 2.5 \mathrm{~mm}$ wide were then cut from these pathways and used to form the alternate arms of Y-mazes. A section of strip traversed by either of the treatments groups was used to form the stem of the maze, alternated for each successive test. Sections were used only once and the treatment arms alternated to preclude a positional bias. Sixteen replicates were conducted to compare the response of larvae to arms of mazes bearing either the trail of one larva or 10 larvae, and to arms bearing the trails of either 5 larvae or 10 larvae.

\section{Response of Larvae to Lures}

A study of the processionary caterpillar T. pityocampa (Fitzgerald, 2003) showed that the caterpillars readily follow lures prepared by fastening the integuments of dead caterpillars to sticks. To determine if the larvae of $P$. distigma would show similar behavior, lures were prepared by attaching the eviscerated abdomens of recently killed $P$. distigma larvae to thin dowels. The response of larvae to lures so prepared was observed by moving a lure in front of either an isolated individual or the leader of a procession and observing the extent to which they responded to and followed the lures. A response was considered positive if a larva followed a lure for a distance of at least $5 \mathrm{~cm}$. Lures were held above the card so that there was no possibility of depositing a chemical residue from the lure on the substrate. Following these preliminary observations, attempts were made to draw larvae from well-established trails with a lure to determine the relative importance of pheromonal and tactile cues. A procession consisting of 29 larvae was established on a sheet of paper and the pathway of the procession marked with spaced pencil dots for a distance of approximately $20 \mathrm{~cm}$. A mature larvae was then placed on a section of the trail and allowed to follow it for at least $5 \mathrm{~cm}$ before an attempt was made to lure it off the trail. A response was considered positive if the larva left the established trail and followed 
the lure onto previously unmarked substrate for a distance of at least $5 \mathrm{~cm}$. The test was replicated with 10 different larvae.

\section{Statistical Procedures}

Y-choice experiments were analyzed with chi-square tests using ProStat 2.0 statistical software. Regression analysis of data to determine the effect of age on trail effectiveness was conducted using SigmaStat 1.0 statistical software.

\section{RESULTS}

\section{Formation and Maintenance of Processions}

Processionary behavior is exhibited by all the larval instars of $P$. distigma (Fig. 1C). Under laboratory conditions at approximately $32^{\circ} \mathrm{C}$ processions of near mature larvae advanced at the rate of $4.5 \pm 0.7 \mathrm{~cm} / \mathrm{min}$ ( $N=5$ groups, 18 processions). These processions arose rapidly from unorganized resting aggregations or from cycloalexic formations (Fig. 1D and $\mathrm{E}$ ) in which the larvae always maintained close physical contact, allowing them to tactically and possibly visually monitor the movements of neighbors. When resting larvae detected that neighbors were moving away, they responded by bobbing their heads along the lateral flanks of departing individuals, and then fell in line directly behind them as they passed. In this manner, one by one, the larvae in the assemblage fell into single file alignment and moved away from the resting site, either as a unit or in subgroups of two or more individuals. As the procession moved over the substrate, each larva bobbed its head vigorously against the posterior of precedent individuals. Analysis of close-up video recordings of this behavior showed that larvae moving in procession along branches in the laboratory bobbed their heads $5.3 \pm 0.18$ (SE) times per second $(N=10)$. The behavior occurred when a larva was in direct physical contact with the tip of the abdomen of a precedent individual and stopped if the larva fell behind and lost physical contact with the larva it was following, suggesting that the behavior functions to prod the precedent individual along. Leaders of processions did not bob their heads in this manner. When the procession is in motion, head bobbing is directed primarily at sets of posteriorly directed setae that occur on the lateral flanks of the last two abdomen segments, but if the procession stops, the larvae may crowd each other and bob their heads directly on the dorsal surfaces of the abdomens of precedent individuals. 


\section{Deposition of a Persistent Trail}

While the above observations indicate that mutual tactile stimulation by the larvae plays a role in the establishment and maintenance of processions, additional studies indicated that the maintenance of processions is influenced by a trail marker. Pathways of each of 20 larvae marked with spaced pencil dots on paper cards elicited trail following from other larvae that were placed at pathway origins immediately after they were laid down. The result of this study shows that individual larvae deposit persistent trails as they advance over the substrate that are adequate to orient the locomotive behavior of conspecifics. That persistent trails were laid down on nonhost substrate by recently handled individuals that were not tactically or otherwise influenced by conspecifics suggests that trail marking may be a passive behavior rather than an active, elective process.

Observations of processions established on paper cards showed that when the last caterpillars in these processions were restrained with a small brush so that the processions proceeded without them, the restrained caterpillars followed the precise pathways taken by the processions and eventually caught up with their siblings when released $(N=20)$. Since breaks in the physical connectedness of larvae in processions are inevitable, the deposition of a persistent trail by the larvae serves to hold processions together by facilitating the rebanding of fragments.

\section{Longevity of the Trail Marker}

Pathways of larvae moving in tandem elicited trail following by other larva placed at their origins $0.5,1$, and $2 \mathrm{~h}$ after their deposition but not after $4 \mathrm{~h}$. Regression analysis of the data indicates that the trails decline in effectiveness linearly with time (Fig. $2, R=0.998, P=0.001$ ). In the 2 nd year of our study we repeated this experiment by testing the response of larvae to similarly deposited trails that had aged either 0.5 or $4 \mathrm{~h}$. In these tests, all of 10 larvae followed trails aged $0.5 \mathrm{~h}$ but none followed trails aged $4 \mathrm{~h}$. We also assessed the persistence of trails deposited on Guazuma leaves. After $0.5 \mathrm{~h}, 8$ of 10 trails were followed by test larvae but none of the trails elicited trail following after $4 \mathrm{~h}$.

\section{Response of Larvae to Whole Body Extracts}

The results of the studies reported above show that larvae of $P$. distigma deposit a persistent trail as they advance over the substrate. 


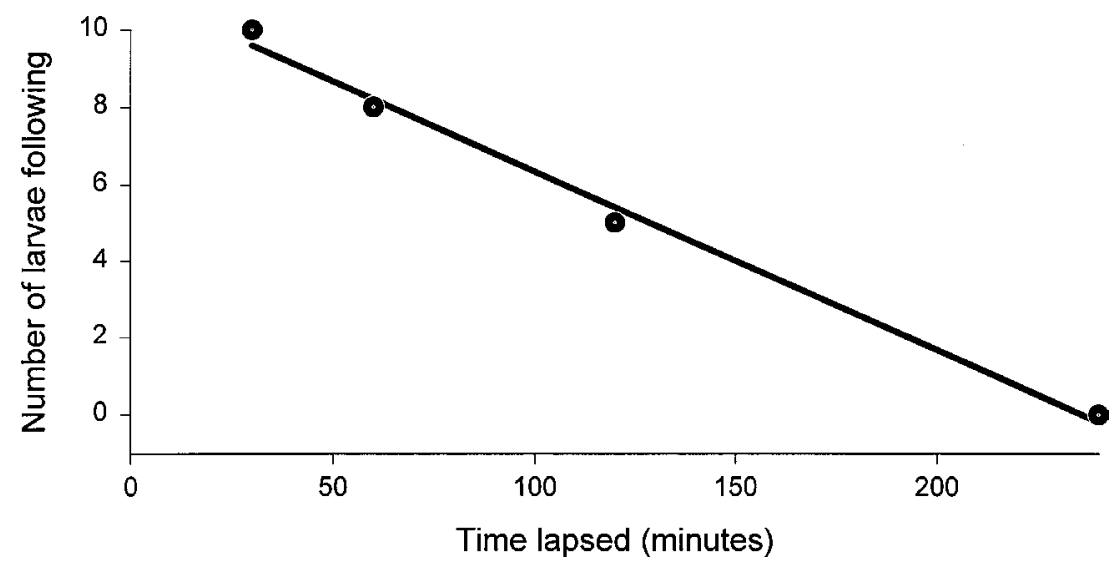

Fig. 2. Number of $P$. distigma larvae following pathway of a two-larval procession at each of four time intervals after the deposition of the pathway. $N=10$ replicates per time interval.

Although the prepupal larvae of $P$. distigma secrete silk from anal glands to create protective shells when they pupate (Janzen, 1979), the earlier instars do not produce silk and the material is never used as a component of the larval pathway as it is in the Lepidoptera. Trails laid down on leaves could not be washed away with water indicating that they are largely water insoluble ( $N=6$ replicates). Preliminary screenings of whole body solvent extracts of larvae showed that artificial trails prepared from ethanol, acetone, ether, and hexanes all elicited some degree of following from the larvae but the most consistent response was shown to the acetone extract. In a follow-up series of two-choice tests, all of 10 larvae chose arms treated with $5 \mu \mathrm{l}$ of a stock acetone solution over solvent control arms $\left(\chi^{2}=10, P<0.01\right.$; Fig. $1 \mathrm{~A}$ and B). Larvae also readily followed 4-cm-long trails prepared by laying out $5 \mu \mathrm{l}$ of the stock acetone extract in narrow lines on paper cards $(N=5$ replicates $)$. They followed artificial trails prepared in the same manner when the stock solution was diluted by an order of magnitude with acetone, but were markedly more hesitant. When following artificial trails the larvae swung the anterior sections of their bodies from side to side as they progressed along the trail, a behavior indicative of chemoklinotactic orientation. Larvae showed no response to artificial trails of $5 \beta$-cholestane-3-one, a chemical previously shown to elicit trail following in several species of Malacosoma (Fitzgerald, 1993; Fitzerald and Webster, 1993; Peterson, 1988), Eucheira socialis (Fitzgerald and Underwood, 1998a), and Eriogaster lanestris (Ruf et al., 2001; Ruf, 2002). 


\section{Source of the Trail Marker}

Although previous studies of trail-marking social caterpillars showed that the larvae deposit a trail pheromone by brushing the tips of their abdomens along the substrate, strips of paper attached to the undersides of abdominal segments 7-9 of larvae of $P$. distigma did not prevent the deposition of a trail. In all of five replicates of the test, larvae placed at the origin of the pathways of treated larvae successfully followed their pathways, indicating that the tip of the abdomen is either not the source or not the sole source of the pheromone.

Following these observations, we placed each of 13 different second instar larvae on separately marked pathways of mature larvae and observed that all followed the pathways from their origins until they reached the approximate regions occupied by the centers of the bodies of the mature larvae when they were lifted from the cards. At those points, the second instar larvae stopped abruptly, swung the anterior portions of their bodies in broad arcs in an apparent search for the trail, and then turned back. Because larvae sample the trail intermittently (see below), some may have advanced slightly beyond the actual end of the marked pathway before initially hesitating and turning back. Nonetheless, the results of this study indicated that the marker is secreted from a site or sites as far forward as the third or fourth abdominal segments.

We then attempted to further isolate the site of secretion by gluing paper strips to the ventral surfaces of abdominal segments 3-6 separately and to 3 and 4 together, but none of these procedures prevented the treated larvae from depositing a trail. However, when segments 5 and 6 were blocked together, test larvae failed to follow pathways in five of eight replicates, but in the other three replicates, larvae showed at least some response to the pathways, following them for part or all of their length.

The results of studies comparing the response of larvae to surface residues collected from three different areas on the venter of the abdomen are shown in Fig. 3. The larvae responded significantly more often to residues collected from abdominal segments 5 and 6 than from 3 and 4 $\left(\chi^{2}=5.93, P=0.01\right)$, but while larvae responded more often to residues from segments 5 and 6 than from segments 7-9 the difference was not significant $\left(\chi^{2}=0.60, P=0.44\right)$. The results of this study and the studies reported above are consistent with the possibility that the marker is secreted from the region of segments 5 and 6 and that the more muted response of larvae to segments 7-9 is due to the contamination of these segments with residual pheromone secreted from the more anterior site.

Analysis of videorecordings and direct observations of larvae moving upside down in Petri plates show that the abdominal segments are 


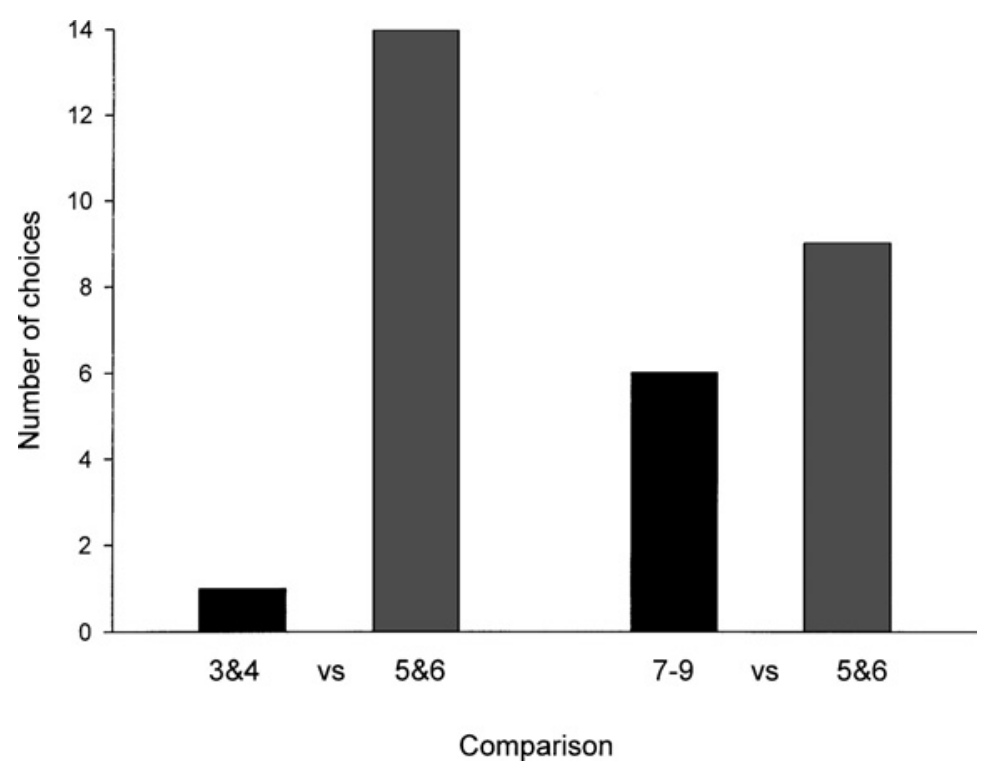

Fig. 3. Response of $P$. distigma larvae to alternative pathways in two separate tests. In one test, response to pathways prepared from surface residue collected from segments 3 and 4 or 5 and 6 was compared. In the other test, response to pathways prepared from surface residue collected from segments 7-9 or 5 and 6 was compared. $N=15$ replicates per test.

completely lifted from the substrate as the larvae locomote so that if only a single point source of secretion were involved, pheromone trails, produced by a process of intermittently "stamping" the substrate, would be discontinuous. The involvement of more than one segment would result in the production of more continuous trails. Also, the head and thorax are completely lifted from substrate and the thoracic legs drawn close to the body during each cycle of locomotion so that the chemosensory structures on the head contact the trail with an intermittency equal to approximately $20 \%$ of the body length. Thus, if the trail is detected by contact chemoreceptors, the pheromone pathway is sampled only intermittently.

Inspection of the ventral surface of the abdomen by light microscopy and SEM showed that the undersurface of the abdomen is smooth surfaced, highly distensible, and lacking any definitive openings or apparent external secretory structures. These observations are consistent with findings for other species of trail-marking social caterpillars subjected to SEM and histological studies (Fitzgerald, 1995; Ruf, 2002) and suggest, as has been postulated for these caterpillar species, that the pheromone of $P$. distigma is produced by epidermal secretory cells. 


\section{Response of Larvae to Trails of Different Strength}

In 16 replicates of tests to compare the response of larvae to arms of Y-mazes marked by either 1 larva or 10 larvae, all of 16 larvae chose the arms marked by 10 larvae $\left(\chi^{2}=16, P=0\right)$. When allowed to choose between arms of Y-mazes marked by either 5 larvae or 10 larvae, 8 of 16 larvae chose each $\operatorname{arm}\left(\chi^{2}=0, P=1.00\right)$.

\section{Response of Larvae to Lures}

Lures prepared by gluing the eviscerated abdomens of recently killed $P$. distigma larvae to thin dowels readily elicited locomotion from both the leaders of processions $(N=15$; Fig. $1 \mathrm{~F})$ and isolated larvae $(N=10$, Fig. 1G). Larvae followed lures held clear of the substrate so that a response to tactile or chemotactile cues associated with the integument of the lure would not be confused with a potential response to a residue of the trail marker that might have been left if the lure was brushed along the substrate. Larvae typically responded immediately to the presentation of the lure, following it precisely when it was held within reach, and hesitated and searched about when it was withdrawn. When lures were moved above their heads, larvae raised the anterior portions of their bodies in attempts to stay in contact with them (Fig. 1F and G). In all of 10 replicates of the test conducted to determine if it was possible to draw larvae off a well-established trail with a lure, the larvae readily followed the lures as they were moved away from the trail and onto unmarked substrate. The results of these studies show that as caterpillars move together in head-to-tail processions, cues derived from the posterior abdomen of the precedent larvae take priority over the trail pheromone in holding the processions together. Since our previous studies indicated that the trail pheromone might be a molecule of low volatile, the possibility must remain that the larvae were responding, at least in part, to the trail pheromone wafting from the model. However, we observed that intermittent contact with the model was necessary for prolonged following to occur and we also observed that a Phelypera larva followed a model prepared in a similar fashion from the integument of the saturniid larva H. lineata.

\section{DISCUSSION}

Aside from the study of $P$. distigma reported here, and a study by Costa et al. (2004), the behavioral basis of processioning has been investigated in only two other insects, the lepidopterans $H$. lineata and $T$. pityocampa. Studies of these two species (Fitzgerald and 
Pescador-Rubio, 2002; Fitzgerald, 2003) and the present study of $P$. distigma show that in all three, larvae, aligned head to tail in processions, physically stimulate the tips of the abdomens of precedent individuals with their heads to promote the forward locomotion of the assemblage. The study of $T$. pityocampa, and the present study of $P$. distigma, also show that tactile or chemotactile stimuli found at the tips of the abdomens of larvae in processions serve to stimulate following behavior. Thus, in these two species, tactile stimuli appear to promote processionary behavior both by drawing larvae forward from the front and by nudging them forward from behind (see also Costa et al., 2004). However, since isolated larvae of $P$. distigma readily followed lures in our experiments (Fig. $1 \mathrm{G})$ as did the larvae of T. pityocampa in previously reported experiments (Fitzgerald, 2003), tactile stimuli applied to the tip of the abdomen are not essential to the elicitation of locomotion in either of these species. The potential role of tactile stimuli in drawing larvae forward remains uninvestigated in $H$. lineata but in this species as well as in T. pityocampa and P. distigma, trail pheromones subserve processionary behavior by allowing stragglers to catch up with processions that have gotten ahead of them. Costa et al. (2004) showed that when the larvae of $P$. distigma move from an old to a new site they typically travel in subgroups with stragglers sometimes not arriving at the new site until as long as an hour after the arrival of the initial contingent. Colonies of $P$. distigma move frequently (Costa et al., 2004) and their fragmentation into permanently isolated subgroups would likely occur in the absence of their trail pheromone.

Trail pheromones are central components of societies' communicative systems and as such their properties can be expected to be fine-tuned to the needs of a colony. Fade-out time may be the single most important feature of a trail pheromone. Trails that persist too long or dissipate too quickly can lead to disorientation and colony fragmentation. The trails of the shelterbuilding, central place foragers, Malacosoma (Fitzgerald, 1995), Eucheira (Fitzgerald and Underwood, 1998a), Gloveria (Fitzgerald and Underwood, 1998b), Thaumetopoea (Fitzgerald, 2003), and Eriogaster (Ruf et al., 2001; Ruf, 2002) all have long-lived components that facilitate the colony's return to profitable feeding sites for days after their initial discovery. They avoid the confusion that might occur if their foraging arenas became cluttered with long-lived trails by incorporating into the trails a labile component that allows them to ascertain relative trail age. Compared to the trail pheromones of these species, the trail pheromone of $P$. distigma is remarkably short-lived. The fade-out time of the trail more nearly resembles that of species of ants that exploit ephemeral food finds (Wilson, 1971) than those of the social caterpillars. The reason for this difference may be that the weevil larvae are nomadic foragers moving only short distances from one 
food find to another. They rest on the leaves they are exploiting between bouts of feeding and typically abandon them only after they are exhausted. Janzen (1979) observed that colonies largely confined their feeding to a single branch tip and Costa et al. (2004) reported that the median distance colonies moved from one feeding site to the next was $4 \mathrm{~cm}$. Moreover, Costa et al. (2004) found that none of 12 colonies of $P$. distigma observed for $20 \mathrm{~h}$ in the field revisited former feeding sites even though they collectively changed sites 26 times. Thus, not only do colonies not require long-lived trails to facilitate their return to food finds, they would likely find themselves repeatedly revisiting exhausted feeding sites were they to employ them.

Processioning is rare compared to trail following and may be a derivative behavior that evolved from the general tendency of trail following caterpillars to stimulate movement in each other by nudging from behind (Fitzgerald, 2003). If this is correct, the behavior may have little or no adaptive value beyond that of trail following. It is an untested possibility, however, that processionary behavior in $P$. distigma has additional value as an antipredator adaptation. Processioning decreases the probability that any one participant will be singled out by a predator in inverse-proportion of the number of individuals in the procession and may allow insects traveling in intimate contact to simultaneously detect a predator and mount an aggregate defense against it.

It has been argued that cycloalexic formations evolve in response to predation pressure and function as antipredator defensive formations (Jolivet et al., 1991; Jolivet and Maes, 1996). The larvae of $P$. distigma readily bite and regurgitate when disturbed whether isolated or in groups. Indeed we often had difficulty moving them with brushes because they locked their mandibles onto the bristles and were not easily dislodged. When cycloalexic formations consist of sufficient numbers of participants, the larvae are protected from lateral attack (Fig. 1E) but their lateral flanks are exposed in smaller aggregations and we observed that stink bugs were able to pierce larva and drag them from the assemblage (Fig. 1D). Janzen (1979) and Costa et al. (2004) also reported attacks by pentatomids, but saw little evidence of successful attacks by other natural enemies.

Cycloalexic formations in $P$. distigma may have coevolved with processionary behavior and side-by-side leaf-margin feeding, both of which are orderly arrangements of larvae. Indeed, Costa et al. (2004) have shown that circular formations readily arise from and collapse into feeding aggregations. The adoption of a circular resting pattern places every member of the colony in intimate lateral contact with other individuals and maximizes the total amount of body contact possible in a two-dimensional aggregation. The arrangement allows a tactile signal arising anywhere 
within the group to be transmitted from one individual to the next and to rapidly radiate through the group. Thus, the entire resting assemblage can be simultaneously alerted to the potential onset of a bout of foraging or to the imminent formation of a procession by even the smallest of tactile disturbances that precede these events. Lending some support to the possibility that there is evolutionary linkage between cycloalexy and processionary behavior is the observation that sawflies in the genus Perga are processionary and also exhibit cycloalexy during the first three larval instars when they are small enough for the whole colony to be accommodated on the flat surface of a leaf. Cycloalexy and processionary behavior, however, are not invariably linked, since the processionary larvae of $H$. lineata do not arrange themselves in circles even though they often rest in the open on the surfaces of leaves.

Whether other species of beetles follow trails or engage in processioning is unknown. Our experience with the phenomenon in the Lepidoptera leads us to believe that despite its spectacular nature, processionary behavior has often gone unreported. The beetles most likely to engage in trail following or processionary behavior are the chrysomelids. The larvae of many species of these beetles are gregarious, and their mobile colonies forage in the open on leaves. Some species also rest in cycloalexic formations (Jolivet et al., 1991). There have been no definitive studies to show that any species of chrysomelid is a trail follower or a processionary, but studies of Plagiodera versicolora by Wade and Breden (1986) and Breden and Wade (1987) suggest that while the movement of the members of a colony from one leaf to another is not synchronized, the larvae may deposit a marker that facilitates aggregation. Too little is known of the foraging behavior of leaf feeding weevils to speculate on whether the behaviors may be expected to have evolved in genera other than Phelypera. The only one of the other 13 species of Phelypera whose foraging behavior has been studied is P. schuppeli (Diniz and Morais, 1996) but the larvae are said not to be processionaries (I. R. Diniz, 2003, personal communication).

\section{ACKNOWLEDGMENT}

The research was supported by NSF (INT 0205841) and CONACyT (J200.441).

\section{REFERENCES}

Breden, F., and Wade, M. J. (1987). An experimental study of the effect of group size on larval growth and survivorship in the imported willow leaf beetle Plagiodera versicolora (Colopetera: Chrysomelidae). Environ. Entomol. 16: 1092-1086. 
Capinera, J. L. (1980). A trail pheromone from silk produced by larvae of the range caterpillar Hemileuca oliviae (Lepidoptera: Saturniidae) and observations on aggregation behavior. J. Chem. Ecol. 6: 655-664.

Costa, J. T., Fitzgerald, T. D., and Janzen, D. H. (in press). Trail-following and natural history of the social caterpillar of Arsenura armida in Costa Rica (Lepidoptera: Saturniidae: Arsenurinae). Trop. Lepidoptera.

Costa, J. T., Fitzgerald, T. D., Pescador-Rubio, A., Mays, J., and Janzen, D. H. (2004). Group foraging behavior of larvae of the Neotropical processionary weevil Phelypera distigma (Boheman) (Coleoptera: Curculionidae: Hyperinae). Ethology 110: 515-530.

Costa, J. T., and Louque, W. (2001). Group foraging and trail following behavior of the redheaded pine sawfly Neodiprion lecontei (Fitch) (Hymenoptera: Symphyta: Diprionidae). Ann. Entomol. Soc. Am. 94: 480-489.

Demolin, G. (1969). Bioécologia de la Processionaria del pino, Thaumetopoea pityocampa Schiff. Incidencia de los factores climaticos. Bol. Serv. Plagas Forest. 23: 9-22.

Diniz, I. R., and Morais, H. C. (1996). Herbivory by the weevil Phelypera schuppeli, feeding on the tree Pachira aquatica and parasitoid attack. Rev. Biol. Trop. 44: 919-921.

Febre, J. H. (1916). The Life of the Caterpillar, Dood, Mead, New York.

Fitzgerald, T. D. (1993). Trail following and recruitment: Response of eastern tent caterpillar Malacosoma americanum to $5 \beta$-cholestane-3-24-dione and 5 $\beta$-cholestan-3-one. J. Chem. Ecol. 19: 449-457.

Fitzgerald, T. D. (1995). The Tent Caterpillars, Cornell University Press, Ithaca, NY.

Fitzgerald, T. D. (2003). The role of a trail pheromone in the foraging and processionary behavior of Thaumetopoea pityocampa. J. Chem. Ecol. 29: 513-532.

Fitzgerald, T. D., and Costa, J. T. (1999). Collective behavior in social caterpillars. In Detrain, C., Deneubourg, J. L., and Pasteels, J. M. (eds.), Information Processing in Social Insects, Birkhauser, Basel, pp. 379-400.

Fitzgerald, T. D., and Pescador-Rubio, A. (2002). The role of tactile and chemical stimuli in the formation and maintenace of the processions of the social caterpillar Hylesia lineata (Lepidoptera: Saturniidae). J. Insect Behav. 15: 659-674.

Fitzgerald, T. D., and Underwood, D. L. A. (1988a). Trail Marking by the larva of the Madrone butterfly Eucheira socialis and the role of the trail pheromone in communal foraging behavior. J. Insect Behav. 11: 247-263.

Fitzgerald, T. D., and Underwood D. L. A. (1988b). Communal foraging behavior and recruitment communication in Gloveria sp. (Lepidoptera: Lasiocampidae). J. Chem Ecol. 24: $1381-1396$.

Fitzgerald, T. D., and Webster, F. X. (1993). Identification and behavioral assays of the trail pheromone of the forest tent caterpillar Malacosoma disstria Hubner (Lepidoptera: Lasiocampidae). Can. J. Zool. 71: 1511-1515.

Floater, G. J. (1996a). Life history comparisions of ground- and canopy-nesting populations of Ochrogaster lunifer Herrich-Schäffer (Lepidoptera Thaumetopoeidae): Evidence for two species. Aust. J. Entomol. 35: 223-230.

Floater, J. G. (1996b). Estimating movement of the processionary caterpillar Ochrogaster lunifer Herrich-Schäffer (Lepidoptera Thaumetopoeidae) between discrete resource patches. Aust. J. Entomol. 35: 279-283.

Flowers, R. W., and Costa, J. T. (2003). Larval communication and group foraging dynamics in the red-headed pine sawfly, Neodiprion lecontei (Fitch)(Hymenoptera: Symphyta: Diprionidae). Ann. Entomol. Soc. Am. 96: 336-343.

Huchon, H., and Demolin, G. (1970). La bioécologia de la processionaire du pin. Dispersion potentielle-dispersion actuelle. Rev. Franc. 22: 220-234.

Janzen, D. H. (1979). Natural history of Phelypera distigma (Boheman), Curculionidae, a Costa Rican defoliator of Guazuma ulmifolia Lam. (Sterculiaceae). Brenesia 16: 213-219.

Janzen, D. H. (1984). Natural history of Hylesia lineata (Saturniidae: Hemileucinae) in Santa Rosa National Park, Costa Rica. J. Kansas Entomol. Soc. 57: 490-514.

Jolivet, P., and Maes, J. M. (1996). A case of cycloalexy in a curculionid: Phelypera distigma (Boheman) (Hyperinae) from Nicaragua. L'Entomologiste 52: 97-100. 
Jolivet, P., Vasconcellos-Neto, J., and Weinstein, P. (1991). Cycloalexy: A new concept in the larval defense of insects. Insecta Mundi 4: 133-141.

Mills, M. B. (1950). Observations on processionary catepillars. W. Aust. Nat. 2: 84-87.

Mills, M. B. (1951a). Bag shelter caterpillars and their habits. W. Aust. Nat. 3: 61-67.

Mills, M. B. (1951b). Bag shelter caterpillars and their habits (Part 2). W. Aust. Nat. 3: 84-92.

Peterson, S. C. (1988). Chemical trail marking and following by caterpillars of Malacosoma neustria. J. Chem. Ecol. 14: 815-823.

Peterson, S. C., and Fitzgerald, T. D. (1991). Chemoorientation of eastern tent caterpillars to trail pheromone 5 $\beta$-cholestane-3-24-dione. J. Chem. Ecol. 17: 1963-1972.

Ruf, C. (2002). Social Life-Styles in Caterpillars: Behavioral Mechanisms and Ecological Consequences, PhD Dissertation, University of Bayreuth, Bayreuth, Germany.

Ruf, C., Costa, J. T., and Fiedler, K. (2001). Trail-based communication in social caterpillars of Eriogaster lanestris (Lepidoptera: Lasiocampidae). J. Insect Behav. 14: 231-245.

Tuskes, P. M., Tuttle, J. P., and Collins M. M. (1996). The Wild Silk Moths of North America: A Natural History of the Saturniidae of the United States and Canada, Cornell University Press, Ithaca, NY.

Van Schagen, J. J., Majer, J. D., and Hobbs, R. J. (1992). Biology of Ochrogaster lunifer Herrich-Schäeffer (Lepidoptera: Thaumetopoeidae), a defoliator of Acacia acuminata Bentham, in the Western Australian wheatbelt. Aust. Entomol. Mag. 19: 19-24.

Wade, M. J., and Breden, F. (1986). Life history of natural populations of the imported willow leaf beetle, Plagiodera versicolora (Coleoptera: Chrysomelidae). Ann. Entomol. Soc. Am. 79: 73-79.

Weinstein, P., and Maelzer, D. A. (1997). Leadership behavior in sawfly larvae Perga dorsalis (Hymenoptera: Pergidae). Oikos 79: 450-455.

Wibmer, G. J., and O'Brien, C. W. (1986). Annotated Checklist of the Weevils (Curculionidae Sensu Lato) of South America (Coleoptera: Curculionoidea). Mem. Am. Entomol. Inst. 39: $\mathrm{xvi}+563 \mathrm{pp}$.

Wilson, E. O. (1971). The Insect Societies, The Belknap Press of Harvard University Press, Cambridge, MA.

Wolfe, K. L. (1988). Hylesia acuta (Saturniidae) and its aggregate pupal pouch. J. Lepidopterists Soc. 42: 132-137. 